\title{
A NECESSIDADE DE SE EVITAR A VITIMIZAÇÃO SECUNDÁRIA
}

\author{
Annunziata Alves Iulianello \\ Promotora de Justiça no Ministério Público \\ do Estado de São Paulo-Brasil \\ annunziatalves@hotmail.com
}

\begin{abstract}
RESUMEN
Na dogmática penal, a vítima, ao longo da história, migrou do papel de protagonista para o de figura esquecida, ocupando, no processo penal, a posição de mera informante. Com a vitimologia moderna, surgiu a necessidade de se conferir maior importância à vítima. A vitimização secundária —efetuada pelas instâncias formais de controle social - está diretamente ligada ao aumento das cifras negras. No presente trabalho, será feita uma breve análise sobre a importância de se evitar a vitimização secundária.

Palabras clave: vítima, processo penal, vitimologia, cifras negras, vitimização secundária.

\section{ABSTRACT}

Traditionally in penal doctrine, victims swapped roles: main character and supporting roles, taking up in penal procedure the role of mere spokesperson. With modern victimology, the need for a more important role on the part of the victim appeared. Secondary victimism - taken by formal instances of social control-is directly connected with an increase in black figures. In this study we will lead a succinct analysis of the importance of avoiding a second victim.
\end{abstract}

Keywords: victim, penal procedure, victimology, black figures, second victim.

\section{ZUSAMMENFASSUNG}

In der Straflebre entwickelte sich das Opfer von der Hauptperson zur vergessenen Figur und erfüllt im Strafprozess die Aufgabe des bloßen Informanten. Durch die moderne Opferforschung (Viktimologie) entstebt die Notwendigkeit, dem Opfer eine größere Bedeutung zukommen zu lassen. Die sekundäre Viktimisierung verursacht durch die offiziellen Instanzen der sozialen Kontrolle - ist direkt verbunden mit der Zunabme der Dunkelziffern. In der vorliegenden Arbeit wird eine kurze Untersuchung zur Bedeutung der Vermeidung der sekundären Viktimisierung vorgenommen.

Schlüsselwörter: opfer, strafprozess, viktimologie, dunkelziffern, sekundäre viktimologie. 
SUMARIO: I. INTRODUÇÃO.-II. O PAPEL DA VÍTIMA NO PROCESSO PENAL: DE PROTAGONISTA À MERA INFORMANTE.-III. VITIMOLOGIA E A NOVA IMPORTÂNCIA DAS VÍTIMAS DE CRIMES.-IV. AS CIFRAS NEGRAS E A VITIMIZAÇÃO SECUNDÁRIA.-V. VÍTIMA E PROCESSO PENAL: A NECESSIDADE DE SE MINIMIZAR A VITIMIZAÇÃO SECUNDÁRIA.-VII. BIBLIOGRAFÍA.

\section{INTRODUÇÃO}

$\mathrm{Na}$ dogmática penal, com o passar de tempo, a vítima passou de protagonista à figura esquecida. A partir do momento em que o Estado trouxe o monopólio do ius puniendi para si, no direito penal, a vítima passou a ser considerada como mero objeto material sobre o qual recai o crime, enquanto, no processo penal, tornou-se mera informante, tendo relevância apenas para fins de reprodução dos fatos. Com o avanço dos estudos da vitimologia, a vítima passou a assumir um papel de importância novamente, sendo certo que, atualmente, ainda, que de forma muito incipiente, é possível falar em uma nova preocupação com as vítimas do crime, especialmente na esfera processual penal.

A vitimização secundária - promovida pelas instâncias formais de controle social- encontra no processo penal um solo fértil para que ela ocorra. No presente texto, serão feitas concisas considerações acerca do fenômeno da vitimização secundária, analisando-se como ela está diretamente relacionada às cifras negras, demonstrando-se, assim, a importância de se evitar a revitimização.

\section{O PAPEL DA VÍTIMA NO PROCESSO PENAL: DE PROTAGONISTA À MERA INFORMANTE}

Uma análise histórica do papel ocupado pela vítima no Processo Penal evidencia que ela transitou entre os extremos, exercendo, inicialmente, o papel de protagonista até ocupar a função de mera informante. Neste contexto, a importância da vítima passou a ser limitada à reconstituição do fato criminoso, possibilitando, assim, que o magistrado firme o seu convencimento acerca da ocorrência ou não dos fatos tal como narrados na denúncia.

No que tange aos métodos de solução de conflito, em uma primeira fase, prevaleceu a ideia de vingança privada ilimitada, método primi- 
tivo de solução de controvérsias de cunho penal, pautado precipuamente na noção de retributividade. Diante da ausência de limites, o que ensejava um uso exacerbado da força, ficou evidente que tal modelo acabava comprometendo a subsistência do próprio organismo social, fato que fez com que a própria sociedade vislumbrasse a necessidade de existência de limites, ainda que rudimentares, ao uso da força.

Justamente com base nesta necessidade, de forma natural, surgiram limites à vingança privada, havendo, inclusive, a previsão de formas amigáveis de solução de conflitos, sendo os limites à vingança estabelecidos com base em um critério de proporcionalidade. Neste contexto, a «Lei de Talião», pautada na ideia de «olho por olho e dente por dente» — a qual, atualmente, por razões óbvias, não estaria em consonância com uma pauta mínima de direitos humanos do acusado- no passado, representou uma grande evolução, na medida em que trouxe limites, ainda que rudimentares, como já dito, a uma forma de solução de conflito que outrora era ilimitado ${ }^{1}$.

$\mathrm{Na}$ chamada «Idade de Ouro da Vítima», a qual ocorre após a queda do Império Romano, com respaldo especialmente da Igreja Católica, prevalece a justiça privada, cabendo à vítima a aplicação da sanção, privilegiando-se, ainda, a reparação do dano. A vítima tinha uma verdadeira obrigação de exercer a vingança, pois ela era fundamental para a manutenção da paz social.

Posteriormente, a nova aglutinação do poder anteriormente conferido aos senhores feudais nas mãos dos reis, bem como o crescimento de uma criminalidade em massa acabaram ensejando uma necessidade de modificação do modelo repressivo até então aplicado, passando o Estado a concentrar em suas mãos, de forma paulatina, o direito de punir, até que assumiu o lugar de detentor exclusivo do ius puniendi. É justamente neste cenário que a vítima passa a ter papel absolutamente secundário, de forma que seus interesses — de cunho reparatório ou punitivo— não são mais levados em consideração.

Neste contexto, a antiga noção de dano foi substituída pela noção de infração, sendo a prática de uma infração penal, ou seja, a violação à lei,

\footnotetext{
${ }^{1}$ Neste sentido, as considerações de Guilherme Costa Câmara, o qual, porém, assevera que, mesmo na chamada «Idade de Ouro da Vítima», a posição de destaque conferida à vítima, na realidade, consistia em uma forma de luta pela sobrevivência, pois era uma maneira de se demonstrar a capacidade dissuasória de determinada família ou grupo, prevenindo novos ataques. Não se tratava, portanto, de uma efetiva preocupação alicerçada na noção de responsabilidade penal. Vid. G. C. CÂmara, Programa de política criminal: orientado para a vítima de crime, São Paulo, Revista dos Tribunais-Coimbra, 2008, pp. 30-33.
} 
tida como uma ofensa ao soberano, na condição de representante do Estado. A imposição da sanção, portanto, especialmente no que tange às sanções corporais aplicadas ao acusado, na realidade, era uma maneira de se restaurar, simbolicamente, o poder do soberano, o qual foi lesado em razão da violação à lei. Algum tempo depois, a teoria do bem jurídico acabou, de uma certa forma, contribuindo ainda mais para o afastamento da vítima da dogmática do delito, tendo em vista que o conceito de lesão a bem jurídico acabou afastando a noção de lesão a direito subjetivo.

$\mathrm{Na}$ solução de conflitos de cunho penal, a posição inicialmente pertencente à vítima foi substituída pela figura do procurador. Como os conflitos já não eram mais resolvidos entre as partes, verificou-se a necessidade de se criar um modelo de processo que viabilizasse a reconstrução dos fatos para que o julgamento pudesse ser feito. Surge assim o processo inquisitivo, o qual tem como objetivo, inicialmente, a reconstrução do fato criminoso, possibilitando a imposição de uma sanção pelo magistrado, cabendo a vítima o papel de mera informante. Como a prática do crime é uma ofensa contra o Estado, via de regra, pouco importa a vontade da vítima para que a ação penal seja deflagrada, razão pela qual se tem como regra a ação penal de natureza pública incondicionada. As penas de cunho reparatório em prol das vítimas também perdem importância.

Como consequência deste afastamento da vítima da relação jurídico-penal existente entre o Estado e o acusado, de forma geral, ficou impossibilitada a real solução de conflitos. $\mathrm{Na}$ dogmática penal, a vítima passou a ser mero sujeito passivo ou objeto material em relação ao qual recai a conduta criminosa e, no processo penal, a sua participação ativa foi afastada, assumindo a posição de mera informante. Mesmo com as posteriores evoluções da dogmática penal, especialmente na esfera processual, surgiu a noção equivocada de que, qualquer disposição que tivesse o escopo de proteger a vítima, conferindo-lhe maior participação e maiores direitos no processo, representaria um retorno à ideia de «vingança privada», gerando um ônus excessivo ao acusado ${ }^{2}$.

2 É importante ressaltar que, como será visto mais adiante, uma maior preocupação com as vítimas de crimes não se mostra incompatível com um modelo de Justiça Penal pautada na observância de direitos e garantias fundamentais do acusado. O que se propõe é que se leve em consideração a noção de que a necessidade de resguardo de direitos e garantias fundamentais não deve estar adstrita ao acusado, devendo também ser estendida às vitimas —via de regra, excluída deste âmbito - como uma forma de se viabilizar uma resolução do conflito mais efetiva. Neste sentido, A. Alonso Rimo e C. Villacampa Estiarte, «La víctima en el sistema de justicia penal I», em E. BacA Baldomero, E. Echeburúa Odriozola e J. M. TAMARit Sumalla (coords.), Manual de Victimologia, Valencia, Tirant lo Blanch, 2006, pp. 319-321. 


\section{VITIMOLOGIA E A NOVA IMPORTÂNCIA DAS VÍTIMAS DE CRIMES}

Com o fim da Segunda Guerra Mundial — tendo como pano de fundo as graves violações de direitos humanos, em especial o extermínio de milhões de judeus pelos nazistas-, surgiram os primeiros movimentos vitimológicos, de forma que, no final da década de quarenta, Benjamim Mendelson e Von Hentig despontam como precursores da chamada vitimologia. É a partir deste momento que se passa a considerar que a vítima não pode ser tida como um mero objeto material, neutro e passivo sobre o qual recai o delito. Com base neste raciocínio, nascem as primeiras discussões a respeito da possibilidade da participação da vítima na prática do crime, sendo justamente esta a ideia que permeava a vitimologia tradicional, precursora da atual vitimodogmática ${ }^{3}$.

Por sua vez, a vitimologia moderna, tida pela maioria dos doutrinadores como um ramo da criminologia, tem por objeto o estudo das vítimas de crime ${ }^{4}$, apontando a importância da análise do fenômeno criminoso de forma interdisciplinar. É ligada, portanto, à noção de ciência penal global, demonstrando uma preocupação especial com o aspecto de prevenção das formas de vitimização e com a reparação de danos.

Nas palavras de José Maria Tamarit Sumalla:

«La victimologia puede ser definida hoy, em uma fórmula de síntesis, como la ciencia multidisciplinar que se ocupa del conocimiento relativo a los processos de victimación y desvictimación. Concierne pues a lá victimologia el estúdio del modo em que uma persona deviene víctima, de las

\footnotetext{
3 A vitimodogmática tem por objeto a perspectiva vitimológica na dogmática penal, ou seja, a análise do comportamento da vítima na responsabilidade penal do autor, ou seja, se eventual conduta da vítima pode excluir a responsabilidade penal do autor ou servir para fins de redução da pena a ser aplicada. Vid. J.-M. SiLva SÁnCHEZ, «La consideración del comportamiento de la víctima en la teoría jurídica del delito: observaciones doctrinales y jurisprudenciales sobre la "victimodogmática" », Revista Brasileira de Ciências Criminais, núm. 34 (2011), pp. 166-167.

${ }^{4}$ Embora não se ignore a existência de doutrinadores que entendam que a vitimologia não teria como objeto apenas as vítimas de crimes, abarcando todas as formas de vitimização social e ambiental, como por exemplo, a miséria e as catástrofes naturais, no mesmo sentido defendido por Guilherme Costa Câmara, para fins de evitar uma ampliação excessiva que acabasse comprometendo a própria densidade científica, tem-se que o ideal é que haja uma limitação do objeto, ficando a vitimologia adstrita às vítimas de crimes. Vid. G. C. CÂMARA, Programa de política criminal..., op. cit., pp. 70-71.
} 
diversas dimensiones de lá victimación (primaria, secundaria y terciaria), y de las estrategias de prevención y reducción de la misma, así como del conjunto de respuestas sociales, jurídicas y asistenciales, tendientes a la reparación y reintegración social de la víctima» 5 .

Em que pese a existência de controvérsias, de forma majoritária, tem sido adotado o conceito amplo de vítima, abarcando todos aqueles que, de forma direta ou reflexa, acabam sendo atingidos pelo fenômeno criminoso, englobando ainda a vitimização difusa, como ocorre, por exemplo, em relação aos crimes de colarinho branco e terrorismo.

Com o passar do tempo e de forma paulatina, à medida que os estudos criminológicos foram evoluindo, cada vez mais foi se pensando numa maior necessidade de preocupação com as vítimas. Ao longo do tempo, diante do tratamento conferido à vítima, verificou-se que as instâncias formais de controle social acabavam ampliando os danos morais e sociais que as vítimas sofriam em razão da prática de crime, sendo revitimizadas. Este fenômeno, denominado de vitimização secundária, encontrou no processo penal um campo fértil para a sua ocorrência.

As alterações legislativas relativamente recentes ${ }^{6}$ efetuadas na esfera processual penal pelo legislador brasileiro demonstram ter havido uma certa conscientização da necessidade de se repensar na importância de se conferir um tratamento mais adequado às vítimas de crime, possibilitando que os interesses destas também sejam atendidos e seus direitos, preservados, sem que isso represente um retorno à ideia de vingança privada. Tem sido verificado, ainda, o surgimento de regramentos específicos dirigidos a determinados grupos de vulneráveis, tendo em vista que estes grupos acabam demandando um tratamento especial no curso do processo para que a revitimização seja evitada, como ocorre, por exemplo, com as vítimas menores de idade e com as mulheres vítimas de violência doméstica. Tais disposições legais demonstram que é possível encontrar um equilíbrio entre os interesses do acusado e os da vítima.

No cenário internacional, também é possível constatar uma tendência de se reconhecer direitos às vítimas, especialmente os direitos de informação e de reparação do dano, além de se conferir a elas uma maior partici-

${ }^{5}$ J. M. TAmarit Sumalla, «La victimología: cuestiones conceptuales y metodológicas», e A. Alonso Rimo e C. Villacampa Estiarte, «La víctima em el sistema de justiça penal I», ambos em E. Baca Baldomero, E. Echeburúa Odriozola e J. M. Tamarit SumaLLA (coords.), Manual de Victimologia, Valencia, Tirant lo Blanch, 2006, p. 17.

${ }^{6}$ Como demonstração disso, podem ser citadas as Leis núms. 11.340/06 e 13.431/17. 
pação no processo penal. A título de exemplo da importância que a vítima tem adquirido ao longo do tempo, como referência, pode ser citado o Estatuto Jurídico da Vítima do Delito (Lei núm. 4/2015), vigente no ordenamento jurídico espanhol,

\section{AS CIFRAS NEGRAS E A VITIMIZAÇÃO SECUNDÁRIA}

Em estudo bastante profundo a respeito da importância que as vítimas possuem especialmente para fins de política criminal, Guilherme Costa Câmara afirma que a vítima é a mais importante instância de controle social ${ }^{7}$. Tal afirmação é pautada no fato de que boa parte dos crimes cometidos são levados ao conhecimento das instâncias formais de controle social a partir das declarações da vítima perante a Polícia, o Ministério Público e o Poder Judiciário. Há crimes, portanto, que, sem que a vítima leve a sua ocorrência ao conhecimento das instâncias formais de controle social, muito dificilmente serão investigados e punidos.

Partindo-se da premissa acima mencionada, é fácil concluir que, caso a vítima, de alguma forma, não confie nas instâncias formais de controle social ou tenha receio de ser revitimizada, em inúmeros casos, a ocorrência de determinados crimes raramente chegará ao conhecimento das autoridades, havendo um aumento das chamadas cifras negras.

Um exemplo singelo muito recorrente no Brasil consiste na subnotificação das ocorrências de crimes de roubo praticados nas grandes metrópoles. Muitas vezes, a dificuldade que as vítimas encontram para realizar, por exemplo, o registro de ocorrência de tais fatos nas Delegacias de Polícia acabou contribuindo para o aumento de cifras negras de tais delitos, o que pode ser minimizado, por exemplo, com a possibilidade de realização de registro de ocorrência por meio eletrônico. Acreditar que o fato não será efetivamente investigado, que o seu dano não será reparado ou que o sujeito não será efetivamente punido inegavelmente também são fatores que contribuem para que as vítimas acabem optando por não comunicar os fatos às autoridades.

Ana Sofia Schimidt de Oliveira afirma que, na década de 60, surgiram nos Estados Unidos as denominadas «pesquisas de vitimização», as quais são entregues a uma parte significativa da população a fim de perquiri-la se foram ou não vítimas de determinados delitos, incluindo-se, ainda, per-

7 G. C. CÂmara, Programa de política criminal..., op. cit., p. 86. 
guntas relacionadas ao sistema penal, ao sentimento de segurança e como eles enxergam a qualidade do serviço policial ${ }^{8}$. Manuel da Costa Andrade afirma que, embora existam algumas especificidades, via de regra, o não registro de ocorrência ocorre em razão de três fatores:

«a ineficácia das autoridades policiais (a crença de que denunciar é inútil, incômodo e oneroso), razões ligadas a variáveis situacionais (proximidade entre a vítima e o delinquente, inexpressividade do dano), preservação da privacidade ou temor da exposição (motivos que levam alguns estabelecimentos bancários e hotéis a não denunciar delitos cometidos por empregados e dissuadem vítimas de crimes sexuais ou alguns tipos de estelionato de registrar ocorrência»? .

Uma análise mais acurada, portanto, do fenômeno criminoso em todas as suas dimensões, especialmente sob um enfoque vitimológico, permite concluir que a prática do crime não encerra em si mesma o processo de vitimização daquele que suportou a ação criminosa ou que sofreu o dano reflexo. Esta modalidade de vitimização é denominada de vitimização primária. A prática do crime acaba sendo apenas a primeira fase deste processo, por vezes, infelizmente, não a pior delas, uma vez que a vítima continua sendo reiteradamente revitimizada, especialmente ao buscar as instâncias formais de controle social, ocorrendo, de forma sistemática, a vitimização secundária.

A vitimização secundária é definida como todas as novas agressões psíquicas que a vítima recebe tanto durante a fase de investigação — tratamento inadequado-, quanto durante o processo criminal — falta de informação, de efetiva participação, ausência de reparação do dano, etc. ${ }^{10}$ - .

A ocorrência desta modalidade de vitimização ficou muito nítida, por exemplo, nos casos de crimes praticados no contexto de violência doméstica e familiar contra a mulher, não sendo raros os casos em que as vítimas, por vezes, em solo policial, acabavam sendo revitimizadas ao receberem rótulos degradantes por parte das pessoas responsáveis pelo seu atendimento, não sendo raras as vezes em que sequer o registro de ocorrência era feito. Superada a fase investigatória, no curso do processo, também não raras vezes, a vítima acaba tendo que suportar colocações que tentam atri-

8 A. S. Schimidt de Oliveira, «Vitimologia e Mulher», em M. Reale Junior (coord.) e J. C. Paschoal (org.), Mulher e Direito Penal, Rio de Janeiro, Forense, 2007, pp. 70-71.

${ }^{9}$ M. da C. ANDRADE, A vítima e o problema criminal, separata do volume XXI do Suplemento ao Boletim da Faculdade de Direito da Universidade de Coimbra, Coimbra Editora, 1980, apud A. S. SCHImidT DE OliveIRA, «Vitimologia e Mulher», op. cit., p. 70.

${ }^{10}$ G. C. CÂmara, Programa de política criminal..., op. cit., pp. 83-84. 
buir a ela a responsabilidade pela conduta do acusado. Como uma forma de se tentar superar estes entraves, no Brasil, a Lei 11.340/06, conhecida como Lei Maria da Penha ${ }^{11}$ trouxe previsão acerca da necessidade de delegacias e varas especializadas, com profissionais adequadamente capacitados para o atendimento a este tipo de vitima.

Acerca da vitimização secundária, preciosas as lições de Jesús-Maria Silva Sánchez:

«La Victimología informa de que el funcionamento del sistema jurídico-penal polícia, Derecho, proceso y, más tarde, del sistema social en su conjunto, además de no facilitar la intervención de la víctima como sujeto activo, suele depararle otros prejuicios adicionales a los que representa el hecho de haber sufrido el delito. En primer lugar, por la vía de la llamada "victimización secundaria", que, en algunos delitos puede ser casi tan grave como la primaria: es este el caso de los delitos sexuales, por ejemplo, en los que en ocasiones las defensas adoptan estrategias de culpabilización de la víctima. En segundo lugar, porque es frecuente que frustren las expectativas de obtener un resarcimiento del daño sufrido en el delito: aunque se produzca una sentencia condenatoria para el autor, este es a menudo insolvente, o incluso la condena refuerza su situación de insolvencia, y el Estado carece por el momento de mecanismos para atender a las necessidades de reparación de la víctima» ${ }^{12}$.

As considerações acima tecidas demonstram, portanto, o quanto a vitimização secundária acaba contribuindo para a cifras negras, sendo certo que, especialmente no aspecto processual, deverá haver uma preocupação do legislador e dos operadores do Direito para que a vítima não seja revitimizada.

\section{VÍTIMA E PROCESSO PENAL: A NECESSIDADE DE SE MINIMIZAR A VITIMIZAÇÃO SECUNDÁRIA}

Como já consignado, para uma efetiva resolução de conflitos, a vítima não pode ser vista no processo como uma mera informante ou sujeito passivo do delito. É importante que ela seja vista como um «sujeito de

${ }^{11}$ Lei responsável por trazer mecanismos para coibir a prática de crimes praticados no contexto de violência doméstica e familiar contra a mulher.

12 J.-M. Silva SÁNCHEZ, «La consideración del comportamiento de la víctima...», op. cit., pp. 165-166. 
direitos», possuidora, portanto, de direitos e garantias fundamentais que necessitam de proteção ${ }^{13}$. Aplicando-se o princípio da proporcionalidade, é possível encontrar um ponto de equilíbrio entre vítima e réu, sendo certo que um processo penal preocupado com as vítimas de crimes não é incompatível com a noção de processo penal de cunho garantista.

Acerca da aplicação da contraposição entre os direitos das vítimas e do acusado, Jesús-Maria Silva Sánchez afirma que a vítima e a sociedade teriam o direito, respectivamente, ao restabelecimento de sua dignidade e ao restabelecimento dos vínculos sociais colocados em cheque com a prática do delito. Logo, conclui o citado doutrinador que, na medida em que for possível restabelecer a dignidade da vítima, conferindo-lhe o reconhecimento que ela merece, causando o menor dano possível ao autor do fato, esta deveria ser a orientação a ser seguida ${ }^{14}$. $\mathrm{O}$ crime não pode ser compreendido como uma ofensa à sociedade, sem que haja qualquer preocupação com o ofendido em concreto. Neste cenário, medidas como a possibilidade de conciliação - como ocorre nos crimes de competência dos Juizados Especiais Criminais (art. 74 da Lei 9.099/95) que sejam de ação penal privada e ação penal pública condicionada-, a previsão de reparação do dano na esfera penal —art. 387, IV, do CPP—, maior participação das vítimas nos processos, como a possibilidade de figurar como assistente de acusação, o direito à informação (art. 201, $\$ 2 .^{\circ}$, do CPP), dentre outros disposições representam um maior resguardo dos direitos das vítimas, sem acarretar uma ofensa aos direitos do acusado, minimizando, por conseguinte, a vitimização secundária.

Não se pode deixar de mencionar, ainda, a existência de legislação específica, com um tratamento próprio, de cunho multidisciplinar e específico para determinadas vítimas especialmente vulneráveis. Como exemplo, no Brasil, podem ser citadas a Lei Maria da Penha (Lei 11.340/06) - a qual, muito mais do que uma preocupação em trazer disposições de cunho punitivo, teve o escopo de trazer regulamentação acerca do tratamento que deve ser conferido às vítimas mulheres no contexto de violência doméstica e familiar, tratando-se de um verdadeiro subsistema processual—, bem como a Lei 13.431/17 — teve por objeto estabelecer garantia de direitos da criança e do adolescente vítima ou testemunha de

13 A. Scarance Fernandes, O papel da vítima no processo penal, Rio de Janeiro, Lumen Juris, 2001, p. 56.

${ }^{14} \mathrm{~J}$.-M. Silva SÁNCHEZ, «Una crítica a las doctrinas penales de la lucha contra la impunidad y el derecho de la víctima al castigo del autor», REJ. Revista de Estudios de la Justicia, núm. 11 (2009), pp. 48-49. 
violência, tendo substancial importância nos casos de crianças vítimas de violência sexual-

Acerca da temática, pautado em uma política criminal responsável, na qual vítima e acusado assumem importância no processo penal, preciosas as lições de Guilherme Costa Câmara, o qual afirma que:

«Um conspecto de um processo penal tradicionalmente orientado para o autor, faz-se necessário esmerada elaboração de medidas destinadas a uma maior proteção das vítimas de crime, não com a intencionalidade de recolocá-la numa posição central, mas de conferir-lhe determinados direitos e garantias sem os quais a própria finalidade do sistema jurídico-criminal — perspectivada, como não poderia deixar de ser, à luz da contemporaneidade-, resultaria malograda» ${ }^{15}$.

A maior participação da vítima acaba trazendo um processo penal mais humano, na pois a vítima deixa de ser tida como um mero objeto de exame para ser um sujeito de direitos. ${ }^{16}$ Para minimizar a vitimização secundária, é imperioso que seja concedido às vítimas o direito à informação, a uma maior participação no processo, à reparação do dano, bem como a receber um tratamento adequado, com atuação multidisciplinar, com a presença de psicólogos e assistentes sociais, caso necessário. Somente assim, será possível se evitar o aumento das cifras negras, bem como se obter uma solução de conflito mais justa e mais próxima do que se almeja em termos de pacificação social.

\section{BIBLIOGRAFÍA}

Alonso Rimo, A., e Villacampa Estiarte, C.: «La víctima en el sistema de justicia penal I», em E. Baca Baldomero, E. Echeburúa Odriozola e J. M. Tamarit Sumalla (coords.), Manual de Victimología, Valencia, Tirant lo Blanch, 2006, pp. 306-323.

CÂMARA, G. C.: Programa de política criminal: orientado para a vítima de crime, São Paulo, Revista dos Tribunais-Coimbra, 2008.

FERNANDES, A. S.: O papel da vítima no processo penal, Rio de Janeiro, Lumen Juris, 2001.

García-Pablos de Molina, A., e Gomes, L. F.: Criminologia, 8. ${ }^{a}$ ed., São Paulo, Revista dos Tribunais, 2012.

Greco Filho, V.: Manual de Processo Penal, 7. a ed., São Paulo, Saraiva, 2009.

${ }^{15}$ G. C. CÂmara, Programa de politica criminal..., op. cit., p. 355.

${ }^{16}$ Ibid. 
PaIVA, W. S.: Vitimização, Processo e Reparação: reflexões sobre a participação da vítima na prevenção de delitos, Rio de Janeiro, Lumen Juris, 2014.

Rodrigues, A. P. G.: A Proteção da Vitima no Processo Criminal: aspectos teóricos e práticos, São Paulo, Harbemann, 2012.

SANI, A. I. (coord.): Temas de vitimologia: realidades emergentes na vitimação e respostas sociais, Coimbra, Almedina, 2011.

Scarance Fernandes, A.: O papel da vítima no processo penal, Rio de Janeiro, Lumen Juris, 2001.

Schimidt de Oliveira, A. S.: «Vitimologia e Mulher», em M. Reale Junior (coord.) y J. C. Paschoal (org.), Mulher e Direito Penal, Rio de Janeiro, Forense, 2007.

Silva SÁnchez, J.-M.: «Una crítica a las doctrinas penales de la lucha contra la impunidad y el derecho de la víctima al castigo del autor», REJ. Revista de Estudios de la Justicia, núm. 11 (2009).

- A Expansão do Direito Penal, 2. ${ }^{a}$ ed., São Paulo, Revista dos Tribunais, 2011.

- «La consideracion del comportamiento de la victima em la teoria juridica del delito: observaciones doctrinales y jurisprudenciales sobre la "victimodogmática”», Revista Brasileira de Ciências Criminais, núm. 34 (2011).

TAmarit Sumalla, J. M.: «La victimología: cuestiones conceptuales y metodológicas», e A. Alonso Rimo e C. Villacampa Estiarte, «La víctima em el sistema de justicia penal I», ambos em E. Baca Baldomero, E. Echeburúa Odriozola e J. M. Tamarit Sumalla (coords.), Manual de Victimología, Valencia, Tirant lo Blanch, 2006, pp. 17-50. 